\title{
Effect of Perioperative Blood Transfusion on the Survival of Gastric Cancer Patients Undergoing Laparoscopic Gastrectomy
}

\author{
R. M. LIU, X. H. LIU, G. M. CHENG, W. Q. WANG* AND Y. F. ZHANG ${ }^{1 * *}$ \\ Department of General Surgery, Taikang Xianlin Drum Tower Hospital, No. 188, Lingshan North Road, Nanjing, Jiangsu \\ 210046, China, 'Department of Gastroenterology, Nanjing First Hospital, Nanjing Medical University, No. 68, Changle Road, \\ Nanjing, Jiangsu 210000, China
}

Liu et al.: Effect of Perioperative Blood Transfusion on Survival of Gastric Cancer Patients

\begin{abstract}
Femoral head necrosis is a mobility disorder and till now no satisfactory solution has been reported. The principal contributing factor in the pathogenesis of the disease is insufficient blood supply to the femoral head resulting in necrosis of the femoral head. Various preventive measures required to treat femoral head necrosis include revascularization, adequate supply of osteogenic cells and establishing enough strength to avoid collapse. Among all, cell transplantation therapy is considered the most favourable treatment strategy for femoral head necrosis. However, the results merely depend on the etiology and the clinical stage of femoral head necrosis. Thus, it is better to make a treatment plan according to the epidemiology, disease status and stage. The main objective of this communication is to study the treatment of femoral head necrosis with cell replacement therapy and also its effects by focusing on the disease stages.
\end{abstract}

Key words: Perioperative blood transfusion, laparoscopic gastrectomy, gastric cancer, overall survival, disease free survival

Gastric cancer (GC) is the fourth most common cancer in the world, which is also the second leading cause of cancer death in China. Its main clinical symptoms are abdominal pain, intestinal bleeding or intestinal obstruction necrosis, which is one of the diseases with high mortality at present. So far, the main treatment of GC has been radical gastrectomy. Because a large number of GC patients often have anaemic symptoms and gastrectomy+lymph node dissection sometimes leads to a large amount of blood loss during operation, which is easy to cause adverse reactions during operation, such as low immune function, electrolyte disorder and blood coagulation dysfunction, which brings great risk to the treatment of patients ${ }^{[1,2]}$.

Therefore, blood transfusion (BTF) is a life-saving treatment in the radical resection of GC. Although the demand for BTF is decreasing due to the improvements in surgical techniques and perioperative care ${ }^{[3]}$, many studies have shown that perioperative blood transfusion (PBT) is related to the decrease of overall survival
(OS) and disease-free survival (DFS) in patients undergoing radical resection of $\mathrm{GC}^{[4-6]}$. Some studies have shown that there is a causal relationship and has an effect on the immune system, thereby enhancing immunosuppression ${ }^{[1,7,8]}$. In addition, studies have shown that there is no difference in long-term prognosis between patients undergoing laparoscopic radical gastrectomy and open radical gastrectomy ${ }^{[2,3,9-11]}$. However, compared with laparotomy, laparoscopic gastrectomy has a lower immunosuppressive rate, blood loss and requirement for blood transfusion ${ }^{[11-14]}$.

However, other studies have suggested that BTF is a complex factor rather than a prognostic indicator because it is significantly affected by other factors. Therefore, the relationship between BTF and the prognosis of GC is still controversial. It is believed that the decline in the long-term survival rate of GC patients receiving $\mathrm{BTF}$ is not only caused by $\mathrm{BTF}$, but other reasons might also be involved. It can also be related to the degree of the tumor and other prognostic factors

*Address for correspondence

E-mail: wangwq0430@sina.com 
related to BTF, such as advanced age, difficulty and duration of the operation. This study aims to investigate the risk factors of PBT and its effect on long-term prognosis in patients treated with laparoscopic radical gastrectomy.

\section{MATERIALS AND METHODS}

\section{Patients:}

All patients treated with laparoscopic gastrectomy in Taikang Xianlin Drum Tower hospital from December 2013 to December 2018 were included and divided into the non-transfusion group $(n=58)$ and the blood transfusion group $(n=45)$. All operations were performed by 2 senior surgeons. The patient's age, sex, body mass index, American Society of Anesthesia score, tumor location, tumor, node and metastasis (TNM) stage, conversion to open gastrectomy, postoperative mortality and morbidity in $30 \mathrm{~d}$ and pathological data were collected directly from medical records.

OS and DFS data were collected from the outpatient clinic and patient follow-up data. OS assessment is from the date of operation to the last follow-up or death of any cause. The DFS assessment is from the date of the operation to the time when the cancer relapses or when the patient dies from any cause.

PBT includes all blood transfusions on the day of the operation or $30 \mathrm{~d}$ during hospitalization after operation. Preoperative evaluation included superior gastrointestinal endoscopy, endoscopic ultrasonography, brain, chest and abdominal CT scans and abdominal ultrasound examination. Selected cases were scanned by positron emission computerized tomography (PECT) and bone scan if necessary.

The TNM staging of GC was performed according to the 8th edition of GC TNM staging system issued by the Union for International Cancer Control (IUAC) and American Joint Committee on Cancer (AJCC) in October 2016 $6^{[15-18]}$. Perioperative mortality included deaths within $30 \mathrm{~d}$ after gastrectomy. The postoperative morbidity was classified according to the Clavien-Dindo classification $^{[21-24]}$, the main complications were divided into 3, 4 and 5 grades and the minor complications included 1 and 2 grades.

After discharge, patients were followed up every $3 \mathrm{mo}$ in the first $2 \mathrm{y}$, every $6 \mathrm{mo}$ in the following $3 \mathrm{y}$ and every 6 mo or annually thereafter. Physical examination and routine haematological examinations were carried out during each follow-up. Abdominal CT or abdominal ultrasound and chest X-ray were re-examined 6 mo after the operation. Disease recurrence is defined as local or distant metastasis of cancer cells confirmed by radiation or pathology and the time of diagnosis is determined by the interval between surgery and the last follow-up. The last scheduled follow-up was August 2019. This is a retrospective study, which was approved by the institutional review committee of Taikang Xianlin Drum Tower hospital and the patients signed an informed consent form.

\section{Statistical analysis:}

SPSS 20.0 was used for statistical analysis. The normal distribution data are expressed as mean \pm standard deviation and the differences are analysed using independent t-test. The data of non-normal distribution were expressed as median and range and the differences were compared using the Mann-Whitney U test. MannWhitney $U$ test was used to analyze the difference of semi-quantitative results. Where appropriate, chisquare test or Fisher accurate test was used to analyse the differences in qualitative results.

The survival rate was estimated by the Kaplan-Meier method and the significant difference was determined by the logarithmic rank test. Univariate analysis was used to determine and select the factors that had significant effects on OS and DFS $(p<0.10)$, which were included in the multivariate Cox proportional risk regression model. The adjusted risk ratio (h) and the corresponding $95 \%$ confidence level were used to calculate the confidence interval (CIs). $p<0.05$ is considered to be statistically significant.

\section{RESULTS AND DISCUSSION}

In this study, 103 patients treated with laparoscopic gastrectomy were included. Forty-five patients $(43.7 \%)$ received BTF on the day of gastrectomy or 30 $\mathrm{d}$ during hospitalization after the operation. Compared with patients without PBT, patients who received BTF usually have the characteristics of older age, low preoperative hemoglobin level, advanced cancer, multiple complications, high open radical gastrectomy rate and high incidence of complications within $30 \mathrm{~d}$ after the operation (Tables 1 and 2).

The median follow-up period was 38 mo and 5 patients ( 3 in the blood transfusion group and 2 in the non-transfusion group) lost at each time point. In patients receiving blood transfusions, both OS and DFS decreased significantly (figs. 1 and 2). The cancer stage and multiple complications were independent influencing factors of OS (Tables 3 and 4) and DFS 
TABLE 1: CLINICAL AND PATHOLOGICAL FEATURES OF THE TWO GROUPS

\begin{tabular}{lccc}
\hline Features & Non-transfusion group $(\mathrm{n}=58)$ & Blood transfusion group $(\mathrm{n}=45)$ & $\mathrm{P}$ value \\
\hline Age $(\mathrm{y})$ & $55.71 \pm 11.84$ & $54.98 \pm 11.10$ & 0.516 \\
Gender (male/female) & $39: 19$ & $25: 20$ & 0.700 \\
Preoperative hemoglobin level (g/l)(Range) & $117(81-158)$ & $93(74-148)$ & 0.026 \\
Numbers of complications & & & 0.465 \\
0 & 36 & 29 & 1.000 \\
1 & 14 & 8 & 1.000 \\
2 & 7 & 5 & 0.031 \\
$\geq 3$ & 1 & 3 & 0.687 \\
ASA score & & & 0.731 \\
I & 36 & 34 & 1.000 \\
II & 19 & 9 & 0.189 \\
III & 3 & 2 & 1.000 \\
Number of lymph node dissection & $17(15-29)$ & $14(16-27)$ & 0.625 \\
Residual tumor (R0/R1/R2) & $58 / 0 / 0$ & $45 / 0 / 0$ & \\
Histodifferentiation & & & 32 \\
Differentiation & 34 & 13 & \\
Undifferentiation & 24 & & 0.000 \\
TNM staging & & 2 & 0.086 \\
I & 24 & 24 & 0.000 \\
II & 18 & 19 & \\
III & 16 & &
\end{tabular}

TABLE 2: RESULTS OF SURGERY IN THE TWO GROUPS

\begin{tabular}{lccc}
\hline & Non-transfusion group $(\mathrm{n}=\mathbf{5 8})$ & Blood transfusion group $(\mathrm{n}=\mathbf{4 5})$ & $\mathrm{p}$ value \\
\hline Type of gastrectomy & & & 0.661 \\
Total gastrectomy & 24 & 16 & \\
Distal gastrectomy & 34 & 29 & 0.004 \\
Open radical gastrectomy & 12 & 10 & 0.102 \\
Operation time, min (Range) & $180(140-290)$ & $200(160-280)$ & 0.098 \\
Estimated blood loss, ml (Range) & $210(160-490)$ & 13 & 0.078 \\
Postoperative residence time, d & 10 & 13 & 0.002 \\
30 d postoperative complications & 19 & 2 & 0.879 \\
Serious complications & 4 & 11 & \\
Minor complications & 15 & $180-440)$ & \\
\hline
\end{tabular}

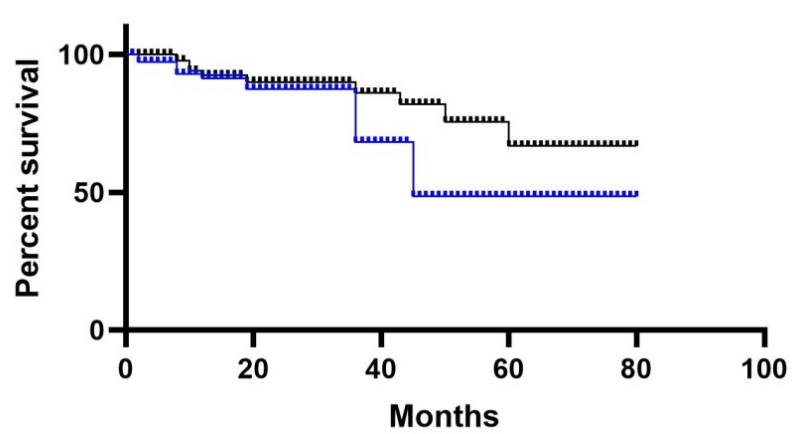

Fig. 1: OS curve of two groups of GC patients

(一匹) Blood transfusion group, (-口-) Non blood transfusion group

(Tables 5 and 6). Patients who received PBT did not find an independent association with a reduced risk of OS or DFS. 
TABLE 3: UNIVARIATE ANALYSIS OF 5-YEAR OS

\begin{tabular}{|c|c|c|}
\hline Variable & $5-y$ OS (\%) & $\mathrm{P}$ value \\
\hline Age $(y)$ & & 0.127 \\
\hline$<65$ & 55 & \\
\hline$\geq 65$ & 41 & \\
\hline Sex & & 0.122 \\
\hline Male & 49 & \\
\hline Female & 38 & \\
\hline ASA scores & & 0.128 \\
\hline$I-I I$ & 51 & \\
\hline III & 37 & \\
\hline Number of complications & & 0.032 \\
\hline No & 59 & \\
\hline Yes & 32 & \\
\hline Type of gastrectomy & & 0.128 \\
\hline Total gastrectomy & 50 & \\
\hline Distal gastrectomy & 42 & \\
\hline TNM staging & & 0.000 \\
\hline$|-I|$ & 65 & \\
\hline III & 32 & \\
\hline Histodifferentiation & & 0.205 \\
\hline Differentiation & 46 & \\
\hline Undifferentiation & 37 & \\
\hline Serious complications & & 0.054 \\
\hline Yes & 54 & \\
\hline No & 41 & \\
\hline PBT & & 0.040 \\
\hline Yes & 48 & \\
\hline No & 40 & \\
\hline
\end{tabular}

TABLE 4: COX PROPORTIONAL RISK MODEL FOR OS

\begin{tabular}{lcc}
\hline Variable & Risk coefficient R & p value \\
\hline TNM staging (I-II VS III) & $2.158(1.269-4.870)$ & 0.018 \\
$\begin{array}{l}\text { Number of complications } \\
(<2 \text { VS } \geq 2)\end{array}$ & $2.510(1.257-4.020)$ & 0.021 \\
\hline
\end{tabular}

low preoperative hemoglobin level, advanced cancer, multiple complications, high open radical gastrectomy rate and high incidence of complications. However, multivariate analysis did not find that BTF was an independent risk factor for re OS or DFS reduction. It has been previously reported that laparoscopic gastrectomy can reduce tissue injury and better protect immune function compared with open gastrectomy ${ }^{[7-10]}$. In theory, reducing tissue damage can reduce the effect of PBT on the immune system, thus reducing OS and DFS.

The amount of blood loss in laparoscopic surgery is usually lower than that in open gastrectomy. A 118 decrease in the BTF rate is not the inevitable result of the reduction of blood loss. However, it is reported that laparoscopic gastrectomy can reduce the volume of PBT and the number of transfusion patients. In this study, the PBT rate was found to be relatively high, which might be related to the patient characteristics and the lack of PBT standard guidelines.

However, comparative studies have shown that patients treated with laparoscopy had less $\mathrm{BTF}^{[7-12]}$. PBT has been shown to increase the risk of postoperative complications rather than laparoscopic surgery. Results of this investigation showed that there is no causal relationship between PBT and poor prognosis after open gastrectomy. Previous reports showed that the

TABLE 5: UNIVARIATE ANALYSIS OF 5-YEAR DFS

\begin{tabular}{|c|c|c|}
\hline Variable & 5-y DFS (\%) & $P$ value \\
\hline Age $(y)$ & & 0.138 \\
\hline$<65$ & 54 & \\
\hline$\geq 65$ & 42 & \\
\hline Sex & & 0.096 \\
\hline Male & 52 & \\
\hline Female & 35 & \\
\hline ASA scores & & 0.189 \\
\hline $\mid-I I$ & 49 & \\
\hline III & 39 & \\
\hline Number of complications & & 0.026 \\
\hline No & 68 & \\
\hline Yes & 42 & \\
\hline Type of gastrectomy & & 0.242 \\
\hline Total gastrectomy & 56 & \\
\hline Distal gastrectomy & 41 & \\
\hline TNM staging & & 0.000 \\
\hline$|-| \mid$ & 71 & \\
\hline III & 36 & \\
\hline Histodifferentiation & & 0.158 \\
\hline Differentiation & 54 & \\
\hline Undifferentiation & 39 & \\
\hline Serious complications & & 0.071 \\
\hline Yes & 59 & \\
\hline No & 44 & \\
\hline PBT & & 0.004 \\
\hline Yes & 55 & \\
\hline No & 38 & \\
\hline
\end{tabular}

TABLE 6: COX PROPORTIONAL RISK MODEL FOR DFS

\begin{tabular}{lcc}
\hline Variable & Risk coefficient R & P value \\
\hline TNM staging (I-II VS III) & $1.805(1.520-2.310)$ & 0.006 \\
$\begin{array}{l}\text { Number of complications } \\
(<2 \text { VS } \geq 2)\end{array}$ & $2.059(1.269-3.350)$ & 0.010 \\
\hline
\end{tabular}

Special Issue 3, 2020 
poor prognosis of patients with GC after PBT is related to the conditions of BTF, but not to the transfusion itself $^{[19-21]}$.

Compared to open gastrectomy, laparoscopic gastrectomy has lower postoperative morbidity, mortality and a similar survival rate in the treatment of $\mathrm{GC}^{[7-9]}$. However, recent evidence suggested that the transformation of patients with $\mathrm{GC}$ has a negative effect on long-term exposure. Interestingly, more patients who received BTF eventually chose open gastrectomy in this study. Compared to transition patients who did not receive open surgery, patients treated with open surgery had poorer baseline characteristics.

Previous studies have explained that the lower survival rate of patients with GC after PBT could be due to the underlying cardiovascular or pulmonary disease, which led to a lower threshold for BTF. In addition, the increase of blood cell count during operation is related to the increase of postoperative mortality. These studies suggested that PBT could improve poor prognosis with or without causality.

It was observed that there was no causal relationship between BTF and prognosis in patients treated with laparoscopic gastrectomy in this study. Similar to the results reported of open surgery, here again it was found that poor health status of BTF patients could be associated with poor prognosis ${ }^{[4-6]}$. Some studies suggested that by reducing BTF and improving surgery, the prognosis can be improved. The advantages of laparoscopic gastrectomy might be related to the need for $\mathrm{BTF}$, which is to protect immune function and reduce intraoperative blood loss. In summary, PBT is associated with decreased OS and DFS in patients treated with laparoscopic radical gastrectomy. This association reflects the clinical condition of patients who needed surgery, but not causality.

\section{Acknowledgements:}

The authors appreciate the support of the Taikang Xianlin Drum Tower Hospital.

\section{Conflict of interest:}

All authors report no conflicts of interest in this work.

\section{REFERENCES}

1. Li B, Liu HY, Guo SH, Sun P, Gong FM, Jia BQ. The postoperative clinical outcomes and safety of early enteral nutrition in operated gastric cancer patients. J BUON 2015;20:468-72.

2. Wen J, Linghu EQ, Yang YS, Liu QS, Yang J, Lu ZS. Associated risk factor analysis for positive resection margins after endoscopic sub mucosal dissection in early-stage gastric cancer. J BUON 2015;20:421-7.

3. Shu B, Lei S, Li F, Hua S, Chen Y, Huo Z. Short and long-term outcomes after gastrectomy for gastric carcinoma in elderly patients. Int J Clin Exp Med 2015;8:13578-84.

4. Elmi M, Mahar A, Kagedan, Law CH, Karanicolas PJ, Lin Y, et al. The impact of blood transfusion on perioperative outcomes following gastric cancer resection: an analysis of the American College of Surgeons National Surgical Quality Improvement Program database. Can J Surg 2016;59:322-9.

5. Reim D, Strobl AN, Buchner, Schirren R, Mueller W, Luppa $\mathrm{P}$, et al. Perioperative transfusion of leukocyte depleted blood products in gastric cancer patients negatively influences oncologic outcome: A retrospective propensity score weighted analysis on 610 curatively resected gastric cancer patients. Medicine 2016;95:e4322.

6. Sun C, Wang Y, Yao HS, Hu ZQ. Allogeneic blood transfusion and the prognosis of gastric cancer patients: systematic review and meta-analysis. Int J Surg 2015;13:102-10.

7. Kosumi K, Baba Y, Harada K, Yoshida N, Watanabe M, Baba H. Perioperative Blood Transfusion, Age at Surgery, and Prognosis in a Database of 526 Upper Gastrointestinal Cancers. Dig Surg 2015;32:445-53.

8. Xu YQ, Jiang TW, Cui YH, Zhao YL, Qiu LQ. Prognostic value of ABO blood group in patients with gastric cancer. J Surg Res 2016;201:188-95.

9. Zhang Y, Qi F, Jiang Y, Zhai H, Ji Y. Long-term follow-up after laparoscopic versus open distal gastrectomy for advanced gastric cancer. Int J Clin Exp Med 2015;8:13564-70.

10. Gu J, Zhao E. Laparoscopic gastrectomy for locally advanced gastric carcinoma: long-term survival outcomes and prognostic factors. Int J Clin Exp Med 2016;9:11485-93.

11. Caruso S, Patriti A, Roviello F, De Franco L, Franceschini F, Coratti A, et al. Laparoscopic and robot-assisted gastrectomy for gastric cancer: Current considerations. World J Gastroenterol 2016;22:5694-17.

12. Aurello P, Sagnotta A, Terrenato I, Berardi G, Nigri G, D'Angelo F, et al. Oncologic value of laparoscopy-assisted distal gastrectomy for advanced gastric cancer: A systematic review and meta-analysis. J Minim Access Surg 2016;12:199208.

13. Suda K, Nakauchi M, Inaba K, Ishida Y, Uyama I. Minimally invasive surgery for upper gastrointestinal cancer: Our experience and review of the literature. World J Gastroenterol 2016;22:4626-37.

14. Nunobe S, Kumagai K, Ida S, Ohashi M, Hiki N. Minimally invasive surgery for stomach cancer. Jpn J Clin Oncol 2016;46:395-8.

15. Yamashita K, Hosoda K, Ema A, Watanabe M. Lymph node ratio as a novel and simple prognostic factor in advanced gastric cancer. Eur J Surg Oncol 2016;42:1253-60.

16. Hase $\mathrm{K}$, Naomoto $\mathrm{Y}$, Ninomiya $\mathrm{M}$, Watanabe M, Omoto T, Wang H. Staging of gastric cancer. Asian Pac J Surg Oncol 2016;2:75-86.

17. Spiliotis J, Efstathiou E, Matsubara A, Osman MM, Choo SP. Molecular biology of gastric cancer. Asian Pac J Surg Oncol 2016;2:86-100.

18. Dong J, Wang W, Yu K, Gao Y, Cheng X, Liu P, et al. Outcomes of laparoscopic surgery for rectal cancer in elderly patients. $\mathrm{J}$ BUON 2016;21:80-6.

19. Cui J, Deng J, Ding X, Zhang L, Zhang R, Wu W, et al. Blood 
transfusion does not affect survival of gastric cancer patients. J Surg Res 2016;200:98-104.

20. Tarantino I, Ukegjini K, Warschkow R, Schmied BM, Steffen $\mathrm{T}$, Ulrich A, et al. Blood transfusion does not adversely affect survival after elective colon cancer resection: a propensity score analysis. Langenbecks Arch Surg 2013;398:841-9.

21. Muller SA, Mehrabi A, Rahbari NN, Warschkow R, Elbers $\mathrm{H}$, Leowardi $\mathrm{C}$, et al. Allogeneic blood transfusion does not affect outcome after curative resection for advanced cholangiocarcinoma. Ann Surg Oncol 2014;21:155-64.

22. Gui R, Tang H, Gao M, Liu J, Huang R, Zhao G, et al. Impact of perioperative blood transfusion on survival of patients undergoing laparoscopic gastrectomy for gastric cancer. J BUON 2017;22:396-402.

23. Li QG, Li P, Tang D, Chen J, Wang DR. Impact of postoperative complications on long-term survival after radical resection for gastric cancer. World J Gastroentero 2013;19:4060.

24. Haga Y, Yagi Y, Ogawa M. Less-invasive surgery for gastric cancer prolongs survival in patients over 80 years of age. Surg Today 1999;29:842-8.

This is an open access article distributed under the terms of the Creative Commons Attribution-NonCommercial-ShareAlike 3.0 License, which allows others to remix, tweak, and build upon the work non-commercially, as long as the author is credited and the new creations are licensed under the identical terms

This article was originally published in a special issue, "Biomedical applications in Pharmaceutical Sciences" Indian J Pharm Sci 2020:82(2)Spl issue3;115-120 